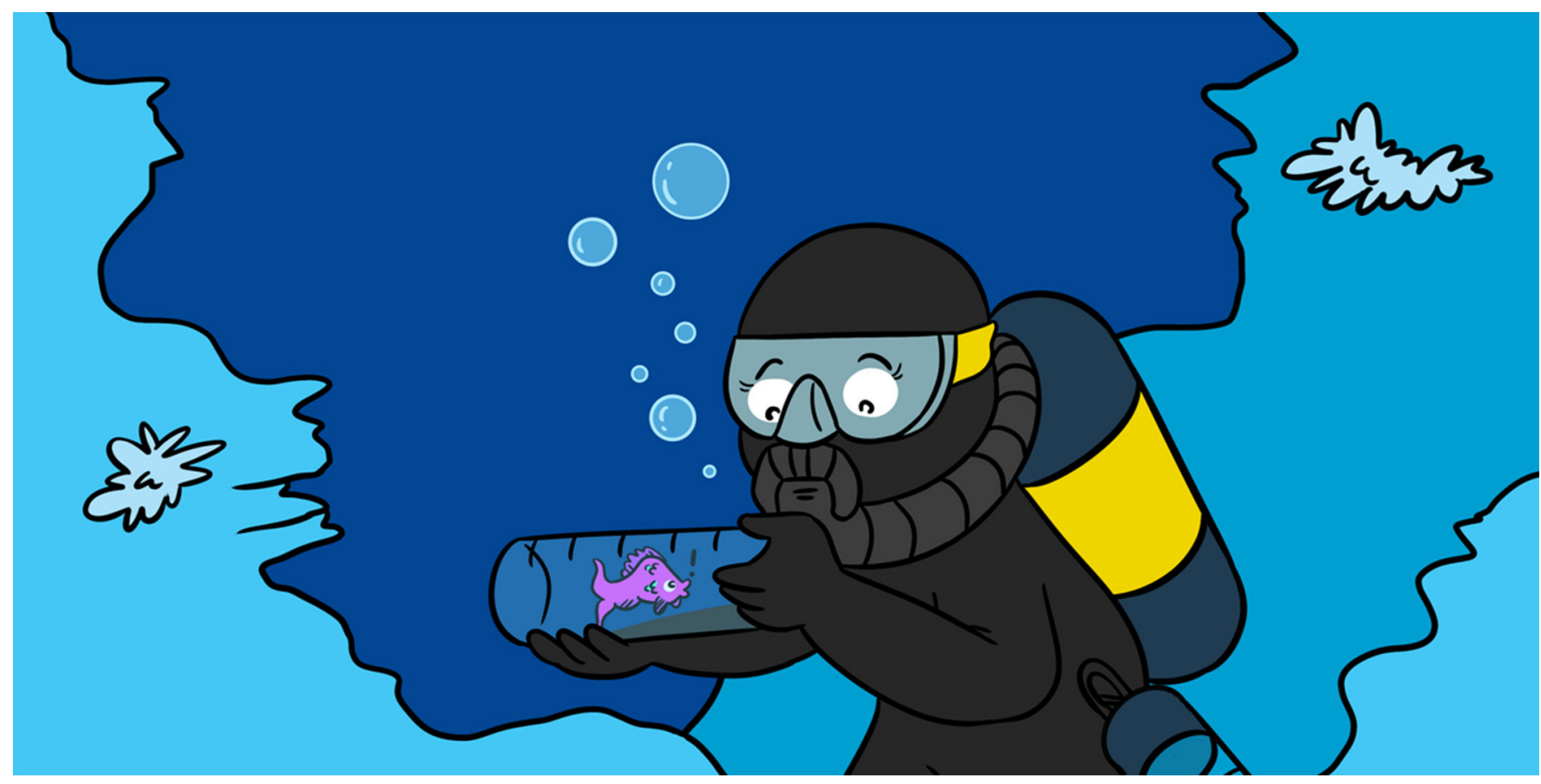

\title{
THE SUBCAS: A PRESSURE CHAMBER FOR FISH
}

\section{Bart Shepherd ${ }^{1 *}$, Hudson T. Pinheiro ${ }^{2}$, Matt Wandell ${ }^{1+}$ and Luiz A. Rocha ${ }^{2}$}

1 Steinhart Aquarium, California Academy of Sciences, San Francisco, CA, United States

${ }^{2}$ Department of Ichthyology, California Academy of Sciences, San Francisco, CA, United States

\section{YOUNG REVIEWERS:}

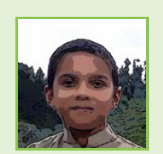

ABDUL

AGE: 12

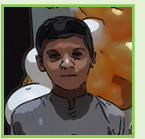

MUHAMMAD

AGE: 10

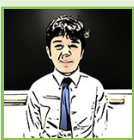

ALI

AGE: 11

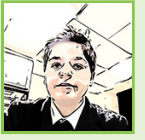

BENJAMIN

AGE: 11
The deeper parts of coral reefs, called mesophotic coral ecosystems, or "the twilight zone," are one of the least explored places on Earth. Our team of scientists uses technical diving equipment to swim into the twilight zone. Because these reefs are so deep, we can only stay there for 15-20 $\mathrm{min}$ on each dive. This is a very short time to study the animals there, so we wanted to bring these animals to our aquarium to study them for a longer time. However, most fish have a gas-filled swim bladder that would pop if we just carried them back up to the surface. We developed a special pressurized chamber that allows us to bring the fishes to the surface without harming them. Using this device, we have collected 174 fishes to study in our aquarium, and to show to the 1.5 million people that visit our museum each year.

\section{CORAL REEFS}

Coral reefs are marine ecosystems found in tropical regions around the world. They cover $<1 \%$ of the ocean, yet they have the highest 


\section{BIODIVERSITY}

A measure of the variety of plant and animal life (the number of species) in an ecosystem or on the entire Earth.

\section{MESOPHOTIC}

Literally "middle-light," the dimly-lit region in between brightly-lit, shallow coral reefs and the dark, deep oceans.

\section{REBREATHER}

A special kind of technical SCUBA diving equipment that recycles air by removing carbon dioxide and adding oxygen, letting the diver breathe the same air over and over again

\section{Figure 1}

The twilight zone is found between 60 and 150 meters (200 and 500 feet) deep, in between shallow coral reefs and the deep, completely dark, aphotic zone. Because scientists cannot use regular SCUBA diving equipment to reach it, and because submersibles are mostly used in deeper waters, the twilight zone is a region where many new discoveries are being made. biodiversity of any marine environment on Earth, sheltering more than a quarter of all of the plants and animals found in the ocean, including fishes, corals and algae. Although scientists have studied shallow coral reefs for hundreds of years, they know almost nothing about deep coral reefs, known as mesophotic coral ecosystems or "the twilight zone" [1]. The twilight zone is found between 60 and 150 meters deep, which is too deep for regular SCUBA diving equipment (Figure 1). Our team of scientists is using rebreathers, advanced diving technology that allows us to visit many deep reefs around the world. Rebreathers recycle and filter your exhaled breath, letting you breathe the same air over and over again.

\section{OUR DISCOVERIES IN THE TWILIGHT ZONE}

In the past, many scientists thought that deep reefs shared similar species with shallow reefs. However, when we started to explore the twilight zone, we found that it was a completely different ecosystem [2]. Deep reefs are darker and cooler, and shelter very different fish communities. In the twilight zone, we are discovering and describing many new animals that have never been seen before [3, 4]. Scientists often use submersibles, like ROVs (remotely operated vehicles) or submarines, to explore the deep ocean. However, these tools are not really the best to study the twilight zone, because their bright lights and loud noises scare away small fishes. It is like trying to use a helicopter to study the birds in the rainforest. Can you imagine that? Instead, the rebreathers let us swim down to 150 m (500 feet) deep. Because we are diving so deep, we can only stay down there for 15-20 min before we must head to

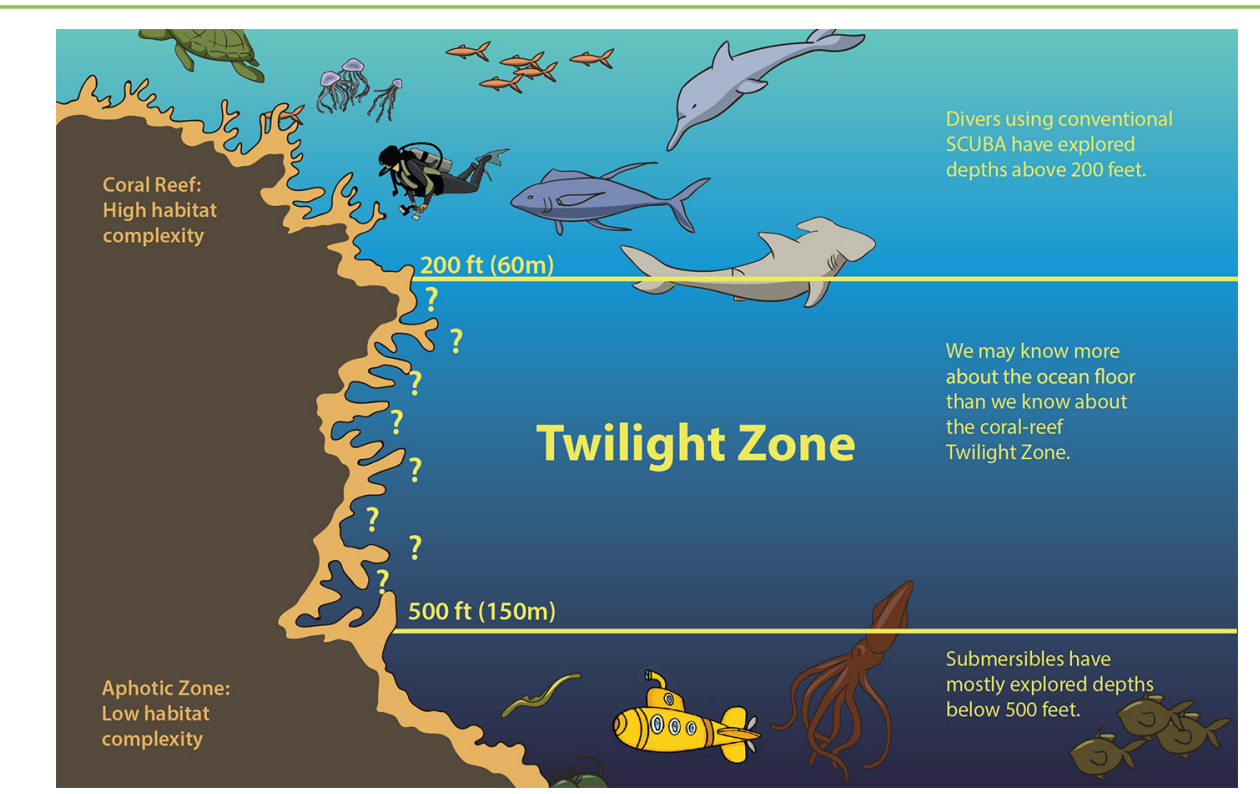

Figure 1 


\section{BUOYANCY}

A force that lifts an object up when it is immersed in water or another fluid

BOYLE'S LAW

An experimental law that describes the relationship between the pressure and volume of a gas. According to Boyle's law, the pressure of a gas increases as the volume of the container decreases. the surface, making safety stops every three meters. With all the safety stops, our dives last from 3 to 5 h, so we only make one dive per day. This gives us a very limited amount of time to study these different and unique fishes. In order to be able to study them for a longer time, we had to bring them with us to the surface, which was a big challenge.

\section{FISH HAVE A BALLOON INSIDE THEIR BODY, AND WE DO NOT WANT TO POP IT}

Many fish have gas-filled swim bladders inside their bodies. They use the swim bladder much like you would use a pool toy or raft to keep part of your body out of the water. Fish can adjust their buoyancy to float up or sink down in the water by adding or removing gas from the swim bladder. They do this by passing gas in and out of special blood vessels. This is similar to the way our lungs work to pull oxygen in from the air we breathe and push out carbon dioxide waste that is circulating in the blood. This process is slow, because a fish can only move a tiny bit of gas across these blood vessels in or out of the swim bladder at any one time.

An important law in physics is Boyle's law. This states that the pressure and volume of a gas are related. If you increase pressure, the volume of gas will decrease, and if you decrease pressure, the volume of gas will increase. We call this an inverse relationship, as it is kind of like a seesaw. If you push down on one side, the other goes up! If we just bring a fish straight up to the surface, the pressure decreases (less water pressing down), so the volume of gas in the swim bladder increases. If we bring a fish up too quickly, the swim bladder could actually pop inside the fish's body. How do you think it would feel to have a balloon inside your body grow bigger and bigger, and maybe even pop?

So that we do not pop the fish, we needed to find a way to keep the pressure constant as we quickly brought the fish to the surface. Once at the surface, we can slowly and safely decrease the pressure on the fish over a period of a few days, letting the fish remove gas from its swim bladder and adjust its buoyancy on its own.

\section{THE SUBCAS: A PORTABLE, SUBMERSIBLE PRESSURE CHAMBER FOR FISH}

In order to keep the fishes under constant pressure and bring them to the surface, we needed a container strong enough to hold this pressure, big enough that the fishes can swim around inside, yet small enough that we can carry it with us while we are diving. The container also needed 


\section{Figure 2}

The SubCAS, or submersible chamber for ascending specimens. (A) The canister filter, which serves as the chamber body; (B) The inner collecting jar, where the fishes are placed: (C) A pressure gauge that shows the depth inside the SubCAS;

(D) The removable top which seals the chamber and locks in the pressure;

(E) A handle to help remove and attach the top; (F) The water inlet where we attach the high-pressure water pump; and (G) The water outlet, which also serves as a second handle to remove and attach the top.

\section{Figure 3}

A rebreather diver places the inner collecting jar (containing fishes) into the SubCAS before ascending from a dive into the twilight zone. to be made of parts that we could easily fix or replace, since we take it with us when we travel around the world. So, we built this container out of a canister filter, something that is used to clean drinking water. We call our invention the SubCAS, a "submersible chamber for ascending specimens" (Figure 2). CAS is also the initials of the museum where we work, the California Academy of Sciences.

We made a special collecting jar that fits inside the canister filter. We collect the fishes with hand nets while we are diving, and we put them in the jar. When we are done diving and ready to head to the surface, we put the jar inside the canister filter, put on the top, and seal it up tightly (Figure 3). One of the most important things for the diver to

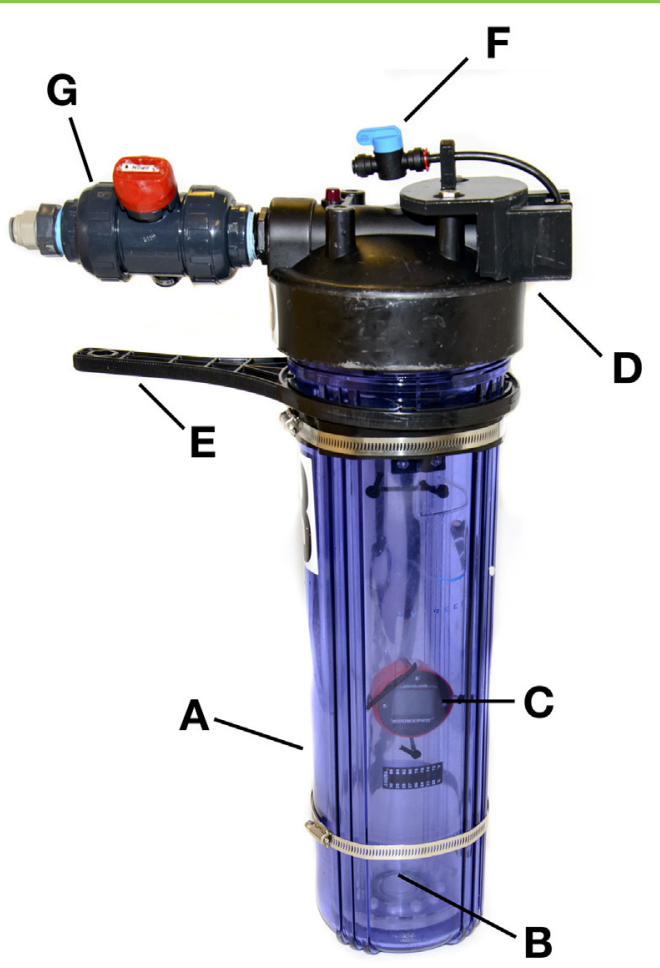

Figure 2

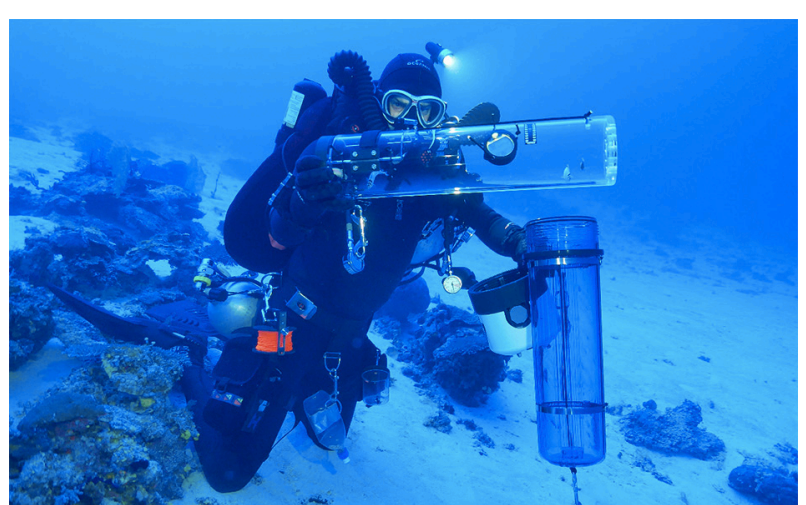

Figure 3 
remember is to put a small bubble of air in the SubCAS with the fishes. This air bubble expands as we head to the surface (remember Boyle's law?), holding the pressure constant inside the SubCAS.

When the divers reach the surface, we connect the SubCAS to a high-pressure water pump. This pump is used to circulate clean, fresh seawater through the chamber so that the fishes can breathe and stay healthy. The high-pressure pump is connected to a control valve that lets us slowly decrease or increase the pressure within the chamber. Over a period of 2-3 days, we slowly decrease the pressure in the system to match the pressure at the surface, where we live. During this time, the fishes remove gas from their swim bladders to adjust their buoyancy to match the changes in pressure. In this way, the fishes are slowly decompressed, and their swim bladders do not pop!

Over 3 years, we traveled to amazing places in the Pacific Ocean to study twilight zone coral reefs, including Vanuatu, the Philippines, Palau, and Micronesia. At these sites, we collected a total of 174 fishes. Using the SubCAS chamber, we were able to bring back more than 150 of these fishes to our aquarium so we could study them to increase our understanding of the twilight zone. We also share them with our visitors to help people appreciate the animals that live in this unique zone.

\section{ANIMAL AMBASSADORS FOR THE MESOPHOTIC}

Today, the fishes that we discovered and continue to study are being taken care of by the biologists of the Steinhart Aquarium, at the California Academy of Sciences in San Francisco, California, USA. The fishes are part of an exhibit called "Twilight Zone: Deep Reefs Revealed," where more than a million people each year learn about the importance of mesophotic reefs and their conservation. The SubCAS fish decompression chamber is also a popular element in this exhibit. Many mesophotic reefs are being affected by overfishing and pollution. Our mission, as scientists, is to explore, explain and sustain life on Earth. The animals that we have collected serve as ambassadors for this mission. We believe that showing the world the beautiful animals from the twilight zone is one of the best ways to raise awareness of the importance of this unknown ecosystem and the need to conserve it.

\section{ORIGINAL SOURCE ARTICLE}

Shepherd, B., Wandell, M., Pinheiro, H. T., and Rocha, L. A. 2018. SubCAS: a portable, submersible hyperbaric chamber to collect living mesophotic fishes. Front. Mar. Sci. 5:187. doi: 10.3389/fmars.2018.00187 


\section{REFERENCES}

1. Pinheiro, H. T., Goodbody-Gringley, G., Jessup, M. E., Shepherd, B., Chequer, A. D., and Rocha, L. A. 2016. Upper and lower mesophotic coral reef fish communities evaluated by underwater visual censuses in two Caribbean locations. Coral Reefs 35:139-51. doi: 10.1007/s00338-015-1381-0

2. Rocha, L. A., Pinheiro, H. T., Shepherd, B., Papastamatiou, Y. P., Luiz, O. J., Pyle, R. L., et al. 2018. Mesophotic coral ecosystems are threatened and ecologically distinct from shallow water reefs. Science 361:281-4. doi: 10.1126/science.aaq1614

3. Shepherd, B., Phelps, T., Pinheiro, H. T., Perez-Matus, A., and Rocha, L. A. 2018. Plectranthias ahiahiata, a new species of perchlet from mesophotic coral ecosystems at Rapa Nui (Easter Island) (Teleostei, Serranidae: Anthiadinae). ZooKeys 762:105-16. doi: 10.3897/zookeys.762.24618

4. Rocha, L. A., Pinheiro, H. T., Wandell, M., Rocha, C. R., and Shepherd, B. 2017. Roa rumsfeldi, a new butterflyfish (Teleostei: Chaetodontidae) from mesophotic coral ecosystems of the Philippines. ZooKeys 709:127-34. doi: 10.3897/ zookeys.709.20404

SUBMITTED: 31 October 2018; ACCEPTED: 18 February 2019; PUBLISHED ONLINE: 07 March 2019.

EDITED BY: Vishal Shah, West Chester University, United States

CITATION: Shepherd B, Pinheiro HT, Wandell M and Rocha LA (2019) The SubCAS: A Pressure Chamber for Fish. Front. Young Minds 7:40. doi: 10.3389/frym.2019.00040

CONFLICT OF INTEREST STATEMENT: The authors declare that the research was conducted in the absence of any commercial or financial relationships that could be construed as a potential conflict of interest.

COPYRIGHT @ 2019 Shepherd, Pinheiro, Wandell and Rocha. This is an open-access article distributed under the terms of the Creative Commons Attribution License (CC BY). The use, distribution or reproduction in other forums is permitted, provided the original author(s) and the copyright owner(s) are credited and that the original publication in this journal is cited, in accordance with accepted academic practice. No use, distribution or reproduction is permitted which does not comply with these terms.

\section{YOUNG REVIEWERS}

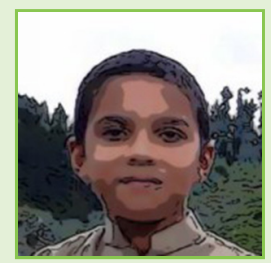

\section{ABDUL, AGE: 12}

I am very much interested in biodiversity with special attention to extinct or endangered species. I like life is oceans, mountains and wish to find in space if any. I had wonderful love for drawing various sceneries of nature. 

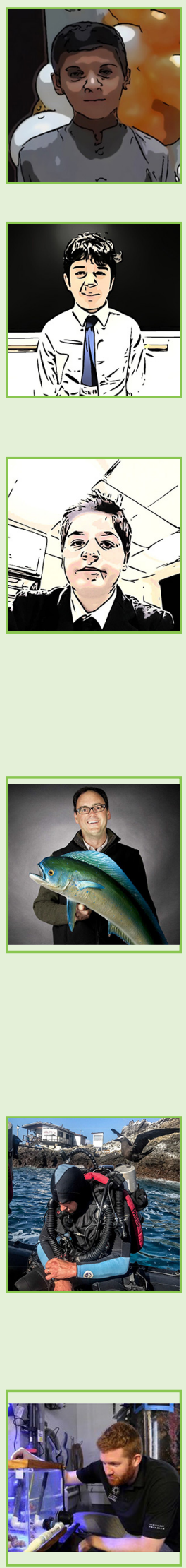

\section{MUHAMMAD, AGE: 10}

I love to draw natural environments, hills, rivers, oceans, and prepare 3D structures airplanes, whales, small machines from playdough. I like the wild animals living in faraway forests where they are not disturbed by humans.

\section{ALI, AGE: 11}

My name is Ali and I come from Livingston in Scotland. My school is Merchiston Castle School in Edinburgh. My parents are from Pakistan. My favorite sports are cricket and cycling. I also like football and I support Arsenal. My favorite subjects are maths and science. I am also learning the piano.

\section{BENJAMIN, AGE: 11}

My school is Merchiston Castle School in Edinburgh. I was born in Paris, I speak French fluently. I am also learning Spanish and Latin. My grandparents live in the middle of the Mediterranean. In NFL I support the Broncos. I am passionate about rugby and I support Scotland. My parents own a tea shop that sells brownies.

\section{AUTHORS}

\section{BART SHEPHERD}

As Senior Director of Steinhart Aquarium at the California Academy of Sciences, I am responsible for the Academy's collection of nearly 40,000 live animals, which range from leaf cutter ants to African penguins. I earned a Masters in Science from Vassar College, studying how eel-shaped fishes swim forward and backward. I am currently conducting research on mesophotic coral ecosystems, coral reproduction, and coral reef restoration. I have two middle-school aged daughters, a cockapoo named D'oggi, and play guitar as often as possible I can when I am not underwater. *bshepherdacalacademy.org

\section{HUDSON T. PINHEIRO}

The study of mesophotic reef fish communities is among my major research interests. I explore biodiversity and evolutionary processes of reef fishes in remote coral reefs and oceanic islands. My current projects involve deep reef fish communities from the Atlantic and Indo-Pacific oceans. I also use my data and knowledge to engage in conservation initiatives, having recently proposed the creation of a Marine Biosphere Reserve and Marine Protected Areas in the Southwestern Atlantic.

\section{MATT WANDELL}

I am a Project Manager at the Monterey Bay Aquarium. I was a biologist at the Steinhart Aquarium, California Academy of Sciences, for nearly 10 years before joining the Monterey Bay Aquarium as an Aquarist. My areas of expertise are coral reef fishes and invertebrates, and innovations in mechanical and technical equipment to advance aquarium science. I am the inventor of the SubCAS fish decompression chamber used in this study.

${ }^{\dagger}$ Present address: Monterey Bay Aquarium, Monterey, CA, United States. 


\section{LUIZ A. ROCHA}

I am the curator of fishes at the California Academy of Sciences. I am a National Geographic Explorer, marine biology professor, have published more than 120 scientific articles and one book, and have spent more than 5,000 hours underwater studying fishes. Currently, my main area of work involves the exploration of twilight zone coral reefs throughout the tropics. I have two teenagers in high-school. 